\title{
Signage AND ERgonomics In PACKAgIng SystemS
}

\author{
Nicoleta Luminiţa Caruţaşu, Victor Adîr, Nicoleta-Elisabeta Pascu, \\ George Căruţaşu Aurel Florin Arion
}
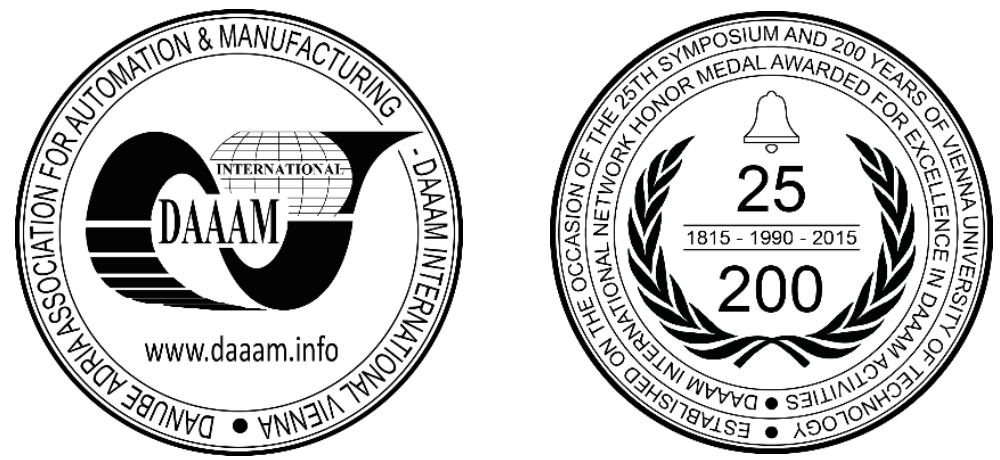

This Publication has to be referred as: Carutasu, N[icoleta] L[uminita]; Adir, V[ictor]; Pascu, N[icoleta-Elisabeta]; Carutasu, G[eorge] \& Florin Arion, A[urel] (2017). Signage and Ergonomics in Packaging Systems, Proceedings of the 28th DAAAM International Symposium, pp.0173-0179, B. Katalinic (Ed.), Published by DAAAM International, ISBN 978-3-902734-11-2, ISSN 1726-9679, Vienna, Austria

DOI: $10.2507 / 28$ th.daaam.proceedings.023

\begin{abstract}
This paper talks about the connection of three important elements of a manufacture process: the human factor, the equipment and the ergonomic strategy. This connection is impossible to be developed without a good signage system which may assure a healthy and secure work place for a user. We have tried to answer to a few questions concerning a manufacture process: How does it work a signage system? What is the place of ergonomics? What's about the connection between them? And, of course, to apply in our research study the principles which lead these main characteristics into a working process (necessity, universality, usability, normativity, simplicity, perceptibility).We have analysed the main characteristics of the human factor and the influence of a lot of elements for the process in a user(human factor)-machine context. In this paper we have explained on a real system the importance of a signage system into an ergonomic strategy. Our study have proposed a few changes for this real system and some recommendations which will assure, in our opinion, a better quality of working, a safety work place and an efficiency of the whole activity of the company. In addition we have developed pictograms to be inserted for every workstation of the manufacture flow.
\end{abstract}

Keywords: Signage; ergonomics; packaging system; principles; pictograms

\section{Introduction}

There are questions and answers about signage system and ergonomics. What means ergonomics? What is a signage system? What is the connection between them? What about the relationship with other disciplines? A lot of papers and books talk about ergonomics and signage tied to the human factor. Ergonomics is a discipline, we may say, which is connected to engineering, design, technology, sociology, psychology and human resources. This kind of science has to exist into a system and for the system to improve quality of life, efficiency of the manufacture process, a healthy and secure work place etc. A manufacture process is tied of many problems including work places, goods, design and human factor. It is well known that the performance of human factor and the usability of products depend, generally, of ergonomics. The signage system comes to help the process to be efficient into an ergonomic strategy. In [1], [2] and [3] there are many papers which discuss about ergonomic and signage system for many cases. Also, in [4] is a lesson about human-centred design and ergonomics and in [5] there are developed examples using signage systems in an ergonomic strategy for airport, museums and exhibitions, schools and libraries, public spaces, culture, congresses and trade fairs (e.g. 
Düsseldorf International Airport, Germany; Fachhochschule Osnabrück, Germany; New 42nd Street Studios/Duke Theater, New York, Schiphol Airport Amsterdam, Netherlands etc.). We affirm that for a safety and healthy work place is necessary to develop an adequate signage system and a clever ergonomic strategy. An efficient signage system has to improve a good and qualified communication using symbols/pictograms, a colour code and information panels. All the graphic representations have to convey a clear message. And a clever ergonomic strategy may include this system to create an efficient connection human factor-manufacture process.

\section{About signage system and ergonomic strategy}

\subsection{The Signage System}

As it is known such a system has to inform, to guide, to allow, to forbid, to warn in different context of the human factor-machine interaction. The designer of such a system has to answer to a few questions, as follows [6]:

- What are the symbols/pictograms for each working position and the quantity of each of them?

- What is the production flow and what kind of machines ?

- Where are the places for these symbols/pictograms concerning the human factor-machine interaction?

- What are the dimensions of the specific sign?

- What is the colour code for the signage system?

- What information panels and quantity are necesarry?

- What kind of information have to be visualized on these panels?

These are the main questions which are waiting answers from the designer. As it is known a signage system is created only if is necessary for an activity. In signage there are two kind of signs: for a general purpose and for specific one. That means general symbols/pictograms and special drawings for specific work places. What is very important is that every graphic representation has to be clear, legible, efficient, working, useful, with an attractive design and, of course, in the right place along the production flow. In this way is realized a safety, secured and healthy work place, for persons and goods. The color code is another important element in a signage system. The colors (red, yellow, blue and green) and shapes where are drawing pictograms are elements which make the difference [7]:

- Red color \& circle shape is translated as interdiction;

- Red color \& triangle shape is translated as compulsory;

- Yellow color \& triangle shape is translated as warning, concern, caution;

- Green color \& rectangle shape is translated as emergency exit, rescue, fire exit;

- Blue color \& square shape is translated as indicative( give an information about something);

- Blue color \& circle shape is translated as indicative;

- Blue color \& rectangle shape is translated as indicative.

\subsection{The Ergonomic Strategy}

In the speciality literature is written like this: "good ergonomics = good economics". And it is true. Because a good ergonomics means: lower injures rates, safety and comfort for the workers, easier jobs, product quality and a reduced fatigue for workers. A bad ergonomics means disorder and risk factors for workers and goods. That means problems in productivity, efficiency, quality and safety. Ergonomics is a science which has the principle of adapting the object to the user. It a science centred on the user to assure a safety and comfortable work place. Ergonomics realize the connection between three main elements of the production system (the human user, the machine/equipment and the environment). It is impossible to create a good production chain without to pay attention to these factors. ,The origins of ergonomics were in the study of workers activities in factories. At the begining the worker it was recepted as machine-like. As the 20 th century progressed, the idea of worker as robot has been largely discredited and ergonomics has centred on health, safety and enhancement of individuals, particularly by focusing on allowing for human differences" [4]. One of the important designers all over the world who was involved in the ergonomic design was Niels Diffrient, an American industrial designer. The Forbes magazine has described this designer as a"granddaddy of the ergonomic revolution"[4].

The ergonomic strategy for an work place is connected to:

- The Human Factor, as the User. What is the activity ruled by him;

- The Machine(equipment), as an Useful Big Tool. What and how works;

- The Environment (the work place and surrounding). The impact of the environment for workers and goods.

The goal of ergonomics is to prevent problems concerning Musculoskeletal Disorders for the workers, fatigue and discomfort for them and to create healthy and safety jobs. And, of course, to develop a competitive organization solving these by using an ergonomic strategy. That means to conceive a Culture of Ergonomics in the company [5] , [8], [9] and [10]. 


\section{Human factor - machine interaction}

\subsection{The human factor, as user}

A human been has a lot of abilities to solve problems at his work. For this he must have knowledge about the production flow and the machines that work. During his job may intervene disfunctions tied by the anathomy and physiology of him, fatigue, discomfort, physics conditions, social communication, psychology etc. He will try to pass over but, many times, the effort is big enough. The solution is good ergonomics to make a satisfied work place, safety, healthy and comfortable. This good ergonomics means to create such a work place knowing the skills, the abilities and the psychology of the workers, and the limits of him. Namely, the right worker in the right place. Another important aspect, connected to the worker, is the work analysis. This analysis has to identify the possible problems which may appear in the production process, the adequate technology, the instrumentation devices, the measurement theory, a signage system etc.

In figure 1 is presented the human factor surrounded by the main characteristics, as part of the human factor-machine system.
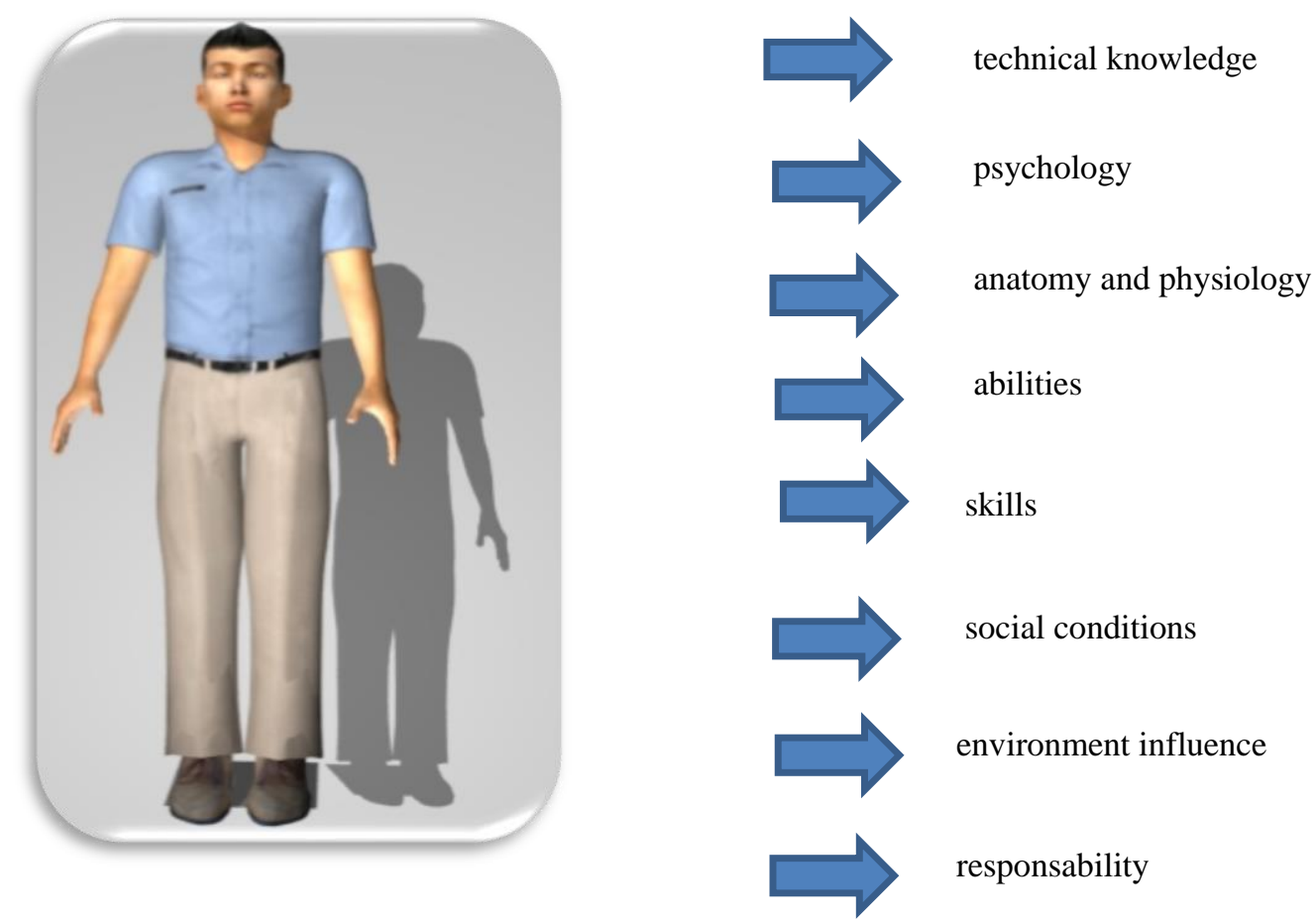

Fig. 1. The main characteristics

\subsection{The machine}

The Machine is a general name for any industrial equipment to product goods. Analysing this part of the system it is possible to have a technical map, concerning tools, devices, technology, systems of charging, labeling, and packaging, if it is stipulated on the production flow. It is an important part because the ergonomic designer has to involve the human factor in a friendly work place. And to design it paying attention to the effects of the environment. Figure 2 is relevant in this way.

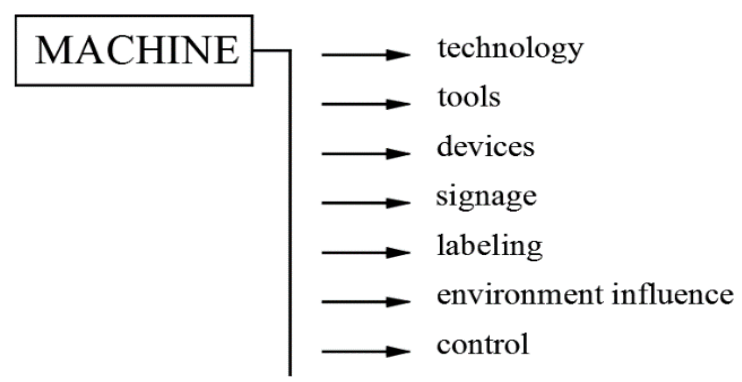

Fig. 2. System 
Figure 3 represents the importance of ergonomics about the human factor - machine interaction. The ergonomics is over the components of the system because its goal is to harmonize the man and the machine in the production process.

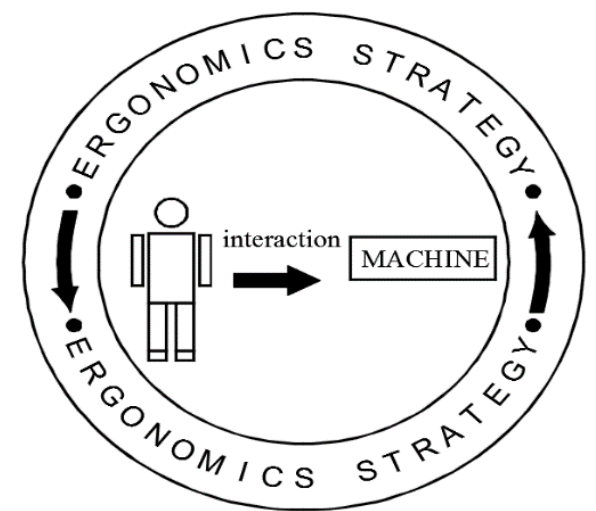

Fig. 3. The ergonomics strategy all over the human factor - machine interaction

\section{Case study - a working and packaging system for walnut oil using glass bottles}

This system has 8 work places, as follows (figure 5):

- 1 - Weighing and Sorting equipment for walnut;

- 2 - Press machine;

- 3 - Decantation;

- 4 - Filtration;

- 5 - Filling;

- 6 - Caping operation - closing bottles operation;

- 7 - Labeling;

- 8 - Packaging.

The bottles are washed in other room and they are brought manually to be introduced in the flow. The technological flow is not automatized, there are workers to do operations and to assure that the process goes on. It is seen that every work place is not „tied” in an integrated and automatized flow, every machine/equipment is separated from others. Only the filling and labeling operations are automatized. Even the caping operation (closing bottles) needs a worker to push a button to assure the operation, bottle by bottle. Finally, there are workers to put bottles in boxes for packaging. flow.

The figure 4 [11], presents the production area and in figure 5 we have represented the scheme of the manufacturing

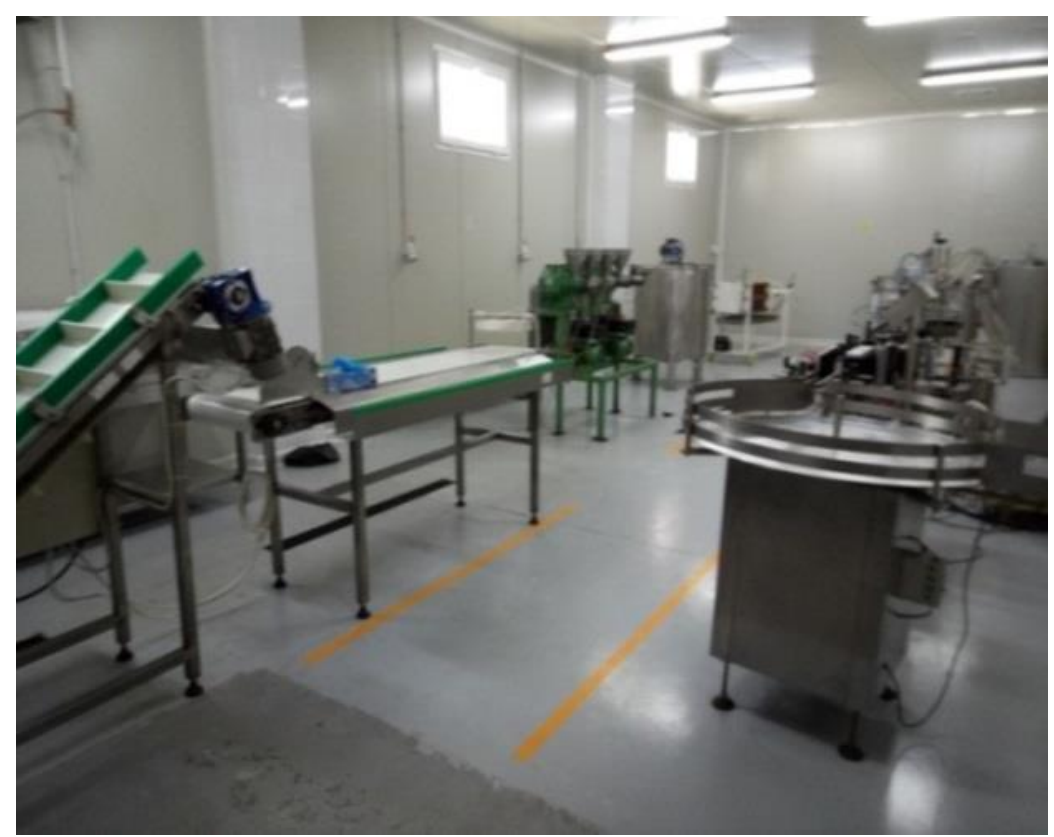

Fig. 4. The working area [11] 


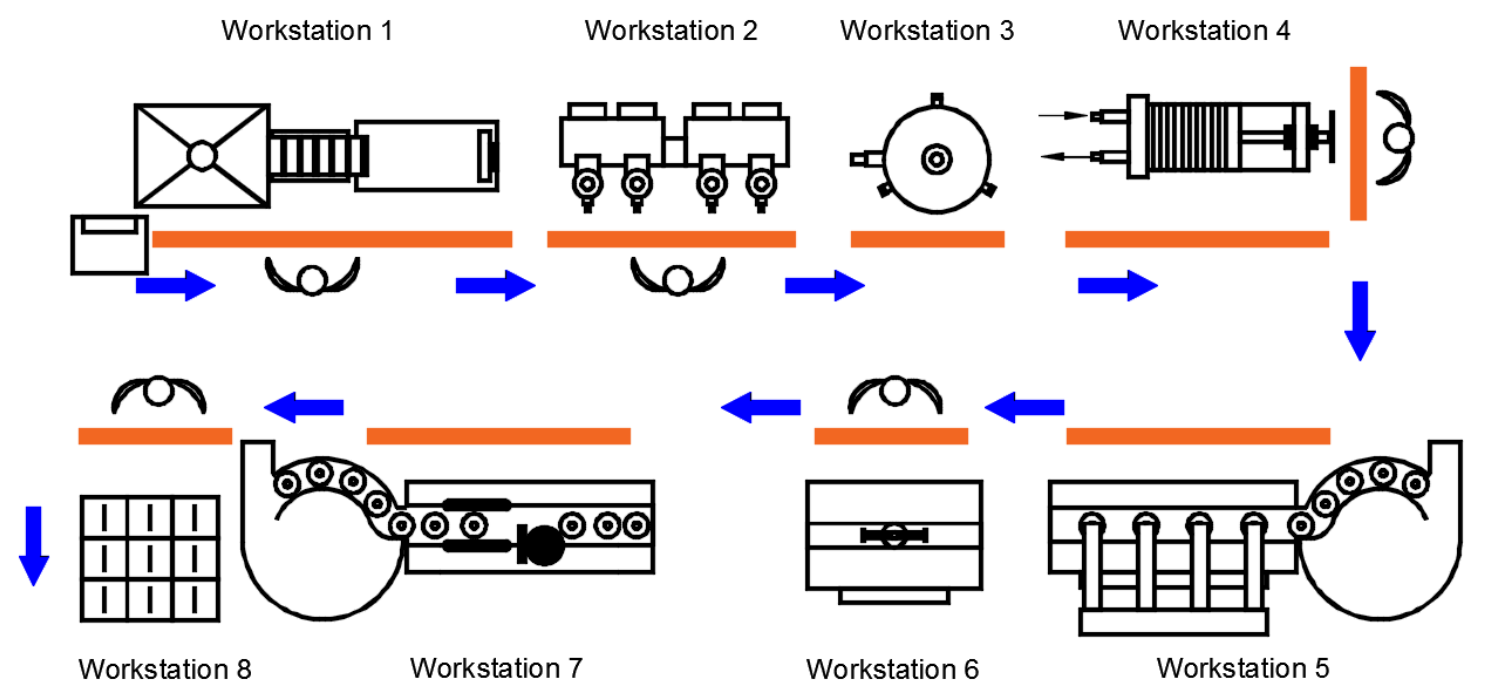

Fig. 5. The manufacturing flow

The critical examination of this process has revealed the necessity of a more implication of the signage-ergonomics concept because pictograms and information/warning panels means more work security and health for employers to avoid the accidents (table 1 and 2).

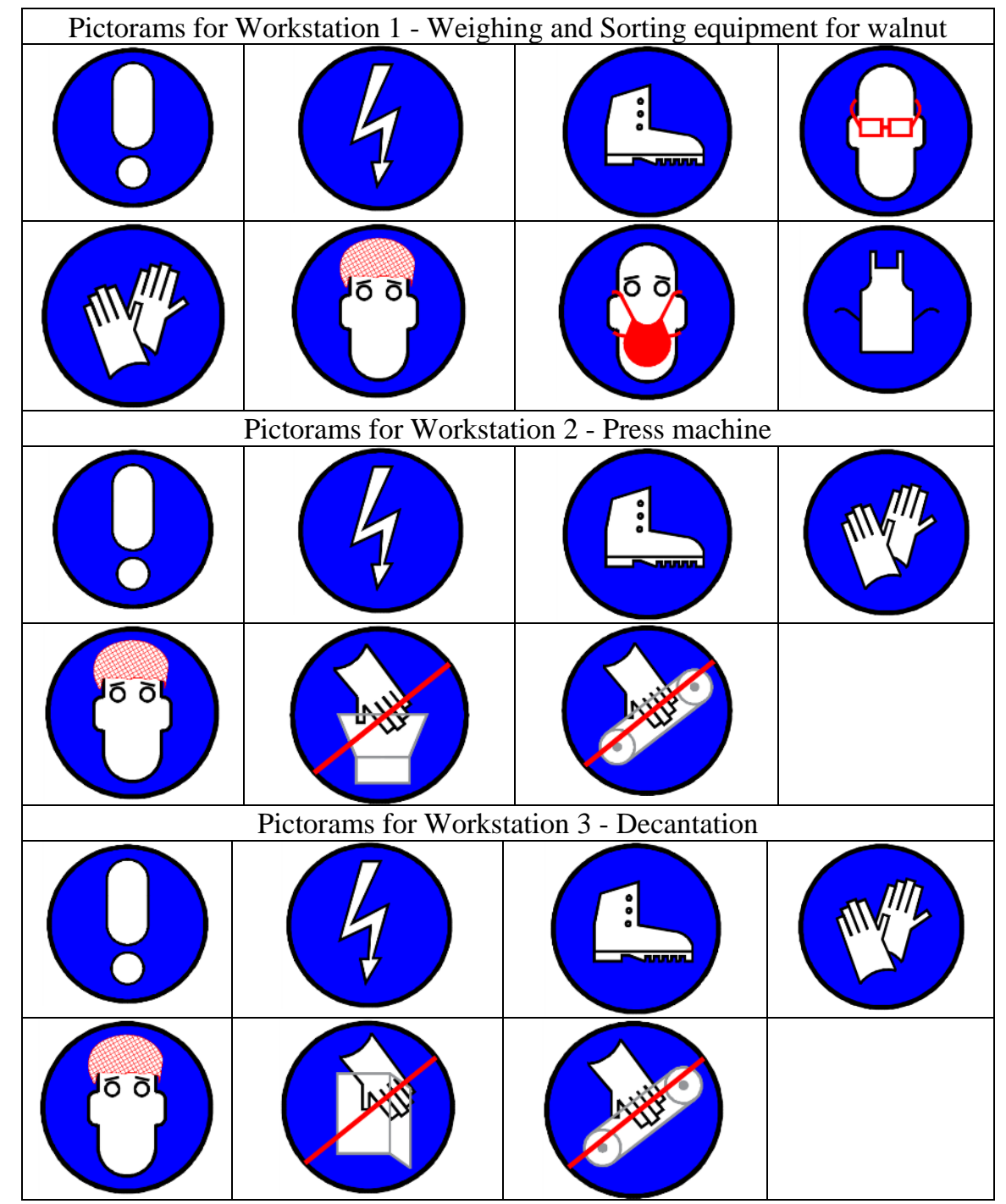

Table 1. Signage 


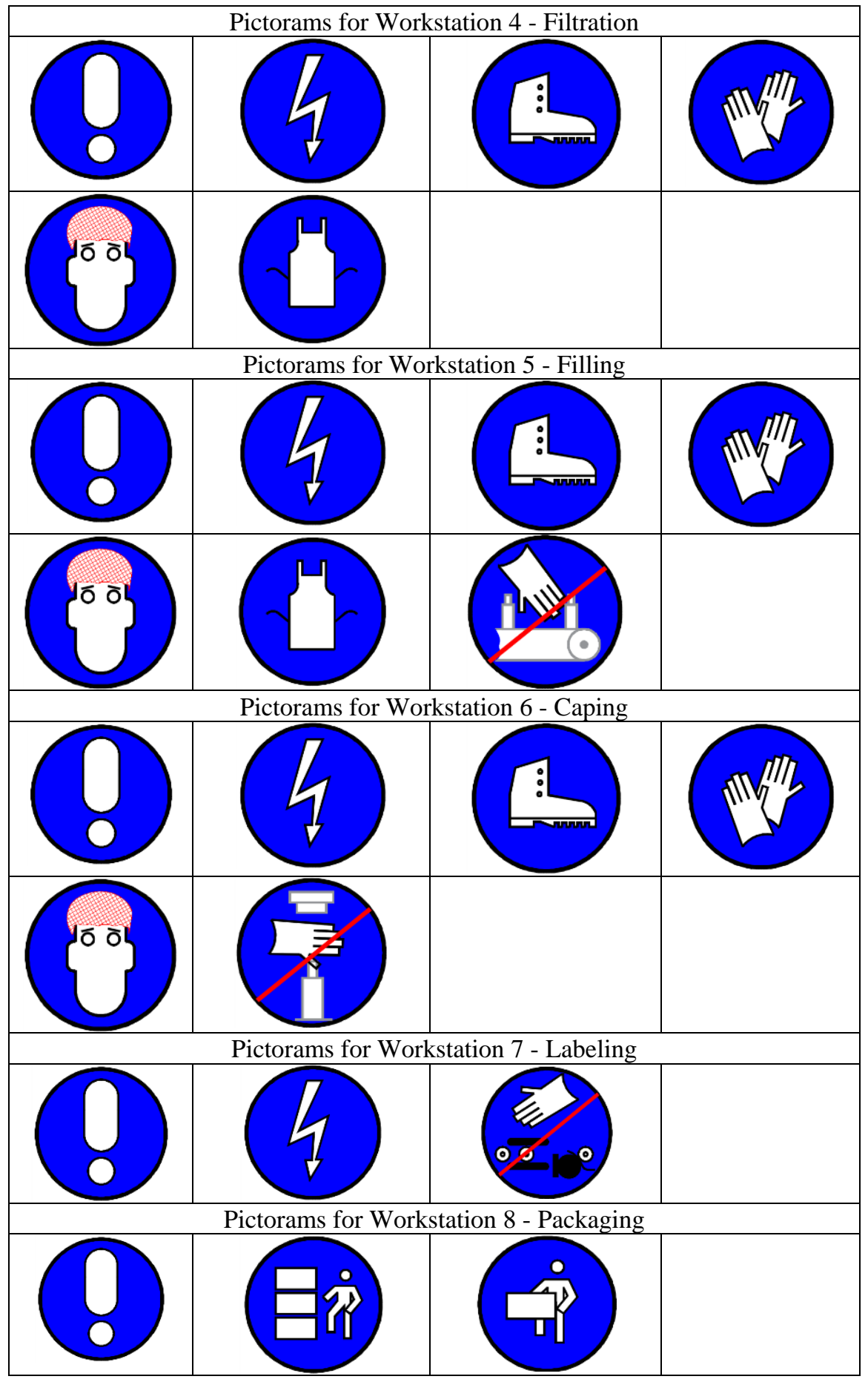

Table 2. Signage

As a result of our research we have made a few recommendations to assure more information and more security, as follows:

- At the entrance to the working area is necessary to be a working flow scheme to familiarize with the workers for each work place. The adecquate pictograms and information panels for each place have to be visual and clear to be understood;

- Also, the existing pictograms in the working area have to be greater and placed in a visual location (for example: do not drop water on a fire is so small and it is hanging on the wall);

- The entrepreneur has to identify the possibility to realized a „tied flow” between filling,caping and labeling working places to develop a continuous and automatized process. Of course that means to increase the efficiency and to specialize one or two workers to serve the process;

- Another recomandation is about the possibility to assure adequate chairs for some work places which allow to sit down; 
- To avoid eye fatigue is important to see if it is possibile to change the eye glasses with glass window in some work places;

- The pictograms and information panels developed for this process have to be exposed in right and visual places to avoid injuries or troubles.

These are the main conclusions from the research study concerning the importance and the consequences connected to the signage-ergonomics concept.

\section{Conclusion}

This research study has become visible following the visit in a SME (small manufacture entreprise) and the discussions about the process flow with the managing staff. We have realised all the process and we have seen the oportunity to improve new elements of signage into an ergonomic strategy, because we have understood the necessity to use better the human factor. It was a challenge for us. First we have established the necessary elements for a adequate signage system. For this purpose we have designed graphic representations for each workstation. We have proposed panels of information at the entrance to familiarize the workers with the signage system and with the process flow. Then we have proposed a ,tied together process"of filling, caping and labeling workstations to be efficent and to reduce the working time. In this SME these three operations were prepared individually, not as an automatic flow. Also, there are workstations which need chairs for workers. It was another recommendation of us concerning the necessity to have them along the process flow, to avoid the fatigue and discomfort for workers and to create a healthy work place. Finally, we have discuss with the entrepreneur and we have analised together the recommendations and the future steps to be implemented in the factory. This research study has created for us the oportunity to develop a kind of guide for these SME, according to their working field. In a future research, of course.

\section{References}

[1] Soares, M.M. \& Rebelo, F. (2017) Ergonomics in Design. Methods \& Techniques. Edited by Marcelo M. Soares and Francisco Rebelo, Published by CRC Press, Taylor Francis Group, Boca Raton, Fl., USA

[2] Advances in Ergonomics in Design, Usability \& Special Populations Part I, (2014), Edited by Marcelo Soares and Francisco Rebelo, Published by AHFE (Advances in Human Factors and Ergonomics) Conference, USA

[3] Advances in Cognitive Ergonomics, (2010), Edited by David B. Kaber and Guy Boy, Published by CRC Press, Taylor \& Francis Group, Boca Raton, Fl., USA

[4] Gareth, W. (2015). DESIGN, an essential introduction, Goodman Fiell, an imprint of the Carlton Publishing Group, ISBN 978178313012 2, London

[5] Andreas Uebele, A. (2007). Signage Systems - Information Graphics. A professional Sourcebook, Thames \& Hudson Ltd., ISBN 978-0-500-28848-1, London

[6] Smitshuijzen, E. (2007). Signage Design Manual, Lars Muller Publishers, ISBN 978-3-03778-096-1, Baden, Switzerland

[7] Abdulah, R. \& Roger Hubner, R. (2006). Pictograms, Icons \& Signs. A guide to information graphics, Thames \& Hudson Ltd., ISBN 978-0-500-28635-7, London

[8] Adîr, V.; Pascu, N.E. \& Adîr, G. (2016). Design de limbaj grafic-vizual. Manualul conceptiei grafice, Editura Printech, ISBN 978-606-23-0693-9, Bucuresti

[9] Berger, M.C. (2009). Wayfinding. Designing and Implementing Graphic Navigational Systems, RotoVision SA, , ISBN 978-2-88893-057-0, Switzerland

[10] Dreyfuss, H. (1984) Symbol Sourcebook. An Authoritative Guide to International Graphic Symbols, John Wiley\&Sons Inc., ISBN 0-471-28872-1, New York;

[11] http://www.magicnuc.ro/, (2017) 